\title{
Periosteal Fibrosarcoma
}

National Cancer Institute

\section{Source}

National Cancer Institute. Periosteal Fibrosarcoma. NCI Thesaurus. Code C66763.

A malignant fibroblastic tumor arising from the periosteal connective tissue that surrounds a bone. 